\title{
Effect of Propane and NaCl-SDS Solution on Nucleation Process of Mine Gas Hydrate
}

\author{
Qiang Zhang, ${ }^{1,2}$ Qiang Wu, ${ }^{2}$ and Hui Zhang' \\ ${ }^{1}$ College of Material Science and Engineering, Harbin University of Science and Technology, Harbin 150080, China \\ ${ }^{2}$ Department of Safety Engineering, Heilongjiang University of Science \& Technology, Harbin 150022, China \\ Correspondence should be addressed to Hui Zhang; hust_zhanghuill@hotmail.com
}

Received 5 May 2017; Accepted 13 July 2017; Published 15 August 2017

Academic Editor: Jin Shang

Copyright ( 2017 Qiang Zhang et al. This is an open access article distributed under the Creative Commons Attribution License, which permits unrestricted use, distribution, and reproduction in any medium, provided the original work is properly cited.

\begin{abstract}
In order to explore the method of accelerating hydration separation process to recover methane from mine gas, propane hydrate phase equilibrium was used to measure the equilibrium points of three kinds of mine gas in $\mathrm{NaCl}$ solution. Driving force was set as $1 \mathrm{MPa}$ on this basis and high-pressure experimental apparatus of mine gas hydrate was used to carry out the nucleation kinetics experiments of mine gas hydrate for three gas samples in different concentrations of sodium chloride ( $\mathrm{NaCl})$ and sodium dodecyl sulfate (SDS) compound systems, which was to study the effect of propane and NaCl-SDS solution on nucleation process of mine gas hydrate. The results showed that induction time of multicomponent mine gas hydrate formation was shortened with the decrease of methane concentration and increase of propane concentration. The induction time of mine gas hydrate formation was shortened with the reduction of $\mathrm{NaCl}$ concentration and the increase of SDS concentration. It was found that methane and propane in multicomponent mine gas nucleated collaboratively, which simplified its nucleation process compared with the single component. $\mathrm{NaCl}$ has two kinds of functions.
\end{abstract}

\section{Introduction}

Methane $\left(\mathrm{CH}_{4}\right)$ is the main component of mine gas, which is an ideal gas fuel. It is colorless and tasteless and its pure calorific value is $34000 \mathrm{KJ}$ per cubic meter. Methane combustion mainly produces carbon dioxide and water. The pollution generated by its combustion only takes up $1 / 40$ that of oil and 1/800 that of coal in general [1]. As a result, methane is regarded as the most realistic and reliable safe energy which is also clean and with high quality. It is reported by Energy Business that the global methane gas resources buried by the depth of $2000 \mathrm{~m}$ are about $2400 \times 10^{12} \mathrm{~m}^{3}$ [2]. In China, this kind of resources is estimated to be $36.8 \times 10^{12} \mathrm{~m}^{3}$, ranking the third in the world, and the amount of recoverable mine gas is about $10 \times 10^{12} \mathrm{~m}^{3}$ [3]. From 2010 to 2015 , the mine gas utilization rate is only $40.91 \%-46.37 \%$ and 46.4 billion $\mathrm{m}^{3}$ methane emissions in total during 6 years is equivalent to that of 94.08 million tons of coal combustion in China [4].

Methane is a kind of strong greenhouse gas with the greenhouse effect being 21 times than that of $\mathrm{CO}_{2}$. The damage to the ozone layer is 7 times that of carbon dioxide [5]. The direct discharge of a large amount of methane not only causes the waste of resources but also pollutes the atmosphere environment. The main reason that a large amount of methane gas cannot be utilized and is directly discharged is that the methane concentration in the extraction mine gas is relatively low and the lack of methane separation and purification technology as well [6]. Mr. Wu et al. proposed that methane could be separated and recovered from extraction mine gas by the method of hydration. The mechanism is that the main components of extraction mine gas are methane, nitrogen, and oxygen and the three kinds of gas can form hydrate, respectively, at a certain temperature and pressure conditions. However, under the same temperature, the pressure of hydrate formation for three gases is extremely different. When it is $273.15 \mathrm{~K}$, the phase equilibrium pressure of methane is $3 \mathrm{MPa}$, nitrogen is $14 \mathrm{MPa}$, and oxygen is $11 \mathrm{MPa}$. Therefore, the methane hydrate can be formed by controlling the pressure to achieve the purpose of separation [7]. 
High separation rate is the key to the separation and recovery of methane from mine gas by the method of hydration [8]. The main factor that restricts the rate of hydration separation is that the induction time of hydration nucleation is longer, so it is necessary to carry out the research on shortening the hydrate induction time. The mine gas hydrate formation in a relatively short time is the key factor in order to meet the needs of industrial production. The nucleation induction time is too long which becomes the main bottleneck of the application of the hydrate technology. Scholars have carried out the research work on how to shorten the induction time. The chemical method of adding accelerator has the advantages of simple process, wherein the anionic surfactant sodium dodecyl sulfate (SDS) is more widely used, and the research work of SDS has been carried out by scholars to promote hydrate formation process.

Karaaslan and Mahmut [9] found that the addition of suitable surfactant in the reaction system could effectively improve the surface tension of the air-water system, speed up the heating process and mass transfer, and promote hydrate formation. This conclusion was confirmed by the experimental study of Zhong and Rogers [10] as well. Then Mohammadi et al. [11] studied the influence of SDS and silver nanoparticles on kinetics conditions of hydrate formation. The results showed that the addition of SDS and silver nanoparticles increased the apparent rate constantly and the mixture of SDS and silver nanoparticles was most effective in enhancing the apparent rate constantly. Link et al. [12] studied the effect of a series of surfactants on the growth rate of methane hydrate and gas storage capacity and found that sodium dodecyl sulfate might be the most suitable surfactant for methane hydrate formation. Then, SDS-kaolin and THF-SDS compounded systems were found to improve the formation rate of mine gas hydrate, and it was better than the superposition of the single additive [1315], which showed that the compound additives had the coordinated effect. Based on the research of $\mathrm{NaCl}$ in the process of hydrate formation, it was identified that $\mathrm{NaCl}$ mainly influenced the thermodynamic conditions [16-18]. However, some scholars found that low concentration $\mathrm{NaCl}$ could promote the hydrate formation and shorten the induction time [19]. Propane can also form the hydrate under a certain temperature and pressure condition, and the hydrate phase equilibrium pressure was lower than that of methane gas under the same temperature condition. Some scholars carried out the hydrate formation experiment utilizing the mixture of methane and propane gas [20,21], and the mixed gas phase equilibrium parameters and the crystal structure of gas hydrate were measured. Prado et al. [22] research showed that hydrate formation of methane and propane mixed gas was faster, and the amount of hydrate was bigger, which indicated that propane can promote the formation of methane hydrate.

To sum up, propane, $\mathrm{NaCl}$, and SDS can improve the methane hydrate nucleation kinetics in certain conditions. However, effect of propane and $\mathrm{NaCl}$-SDS composite system on the hydrate nucleation has not been reported yet. As a result, in terms of the mine gas, it is filled with a certain amount of propane gas, and the phase equilibrium experiment of mixed gas hydrate in the $\mathrm{NaCl}$ system was primarily conducted. Based on the results above, the thermodynamic condition was set up and the mixed gas hydrate nucleation kinetics experiments were carried out in the NaCl-SDS compounded system. The effect of different concentrations of $\mathrm{NaCl}$ and SDS on the mixed gas hydrate nucleation was investigated to explore the distribution law of induction time of mine gas hydrate formation, which helped to analyze the mechanism of $\mathrm{NaCl}$-SDS composite solution and improve the basic theory and method using mine gas hydration separation.

\section{Experimental}

2.1. Apparatus and Material. A visual mine gas hydration curing and high-pressure apparatus was independently developed for the research object of this paper shown in Figure 1.

The experimental apparatus mainly included variable volume high-pressure reactor, $150 \mathrm{ml}$ visual reactor, thermotank, gas booster system, data collection system, and fiber photography system. Variable volume high-pressure reactor was used to measure the phase equilibrium thermodynamic parameters of hydrate and $150 \mathrm{ml}$ visual reactor was utilized to carry out the experiment of hydrate kinetics. The variable volume high-pressure reactor could change its volume within the range of $0 \sim 150 \mathrm{ml}$ continuously, controlled by project control system. The maximum pressure was $30 \mathrm{MPa}$ and the temperature ranged within $-20 \sim 60^{\circ} \mathrm{C}$. The $150 \mathrm{ml}$ visual reactor was a full transparent vessel with an inner volume of $150 \mathrm{ml}$ and a maximum pressure of $20 \mathrm{MPa}$ and the temperature ranged within $-10 \sim 50^{\circ} \mathrm{C}$ in which the mine gas hydrate formation and growth process could be directly observed. Data collection system contained FCC6000 Field Data Server, BT5000 monitor, and configuration software. What is more, the system was equipped with high precision temperature sensor (the range of $-15 \sim 100^{\circ} \mathrm{C}$ and an accuracy of $\pm 0.01^{\circ} \mathrm{C}$ ) and Huba pressure sensor (the range of $0 \sim 25 \mathrm{MPa}$ and an accuracy of $\pm 0.01 \mathrm{MPa}$ ), which could guarantee an accurate experimental measurement.

2.2. Experimental Sample and Reagent. SDS and $\mathrm{NaCl}$ were purchased from Tianjin Kemiou Chemical Reagent Co. Ltd., with the analytical reagent $(\geq 99.5 \%)$. In order to accelerate hydrate formation, a certain concentration of propane was added. The gas samples were as followed:

$$
\begin{aligned}
& \text { Gas sample G1: } \varphi\left(\mathrm{CH}_{4}\right)=55 \%, \varphi\left(\mathrm{CO}_{2}\right)=5 \% \text {, } \\
& \varphi\left(\mathrm{C}_{3} \mathrm{H}_{8}\right)=15 \%, \varphi\left(\mathrm{N}_{2}\right)=22 \%, \varphi\left(\mathrm{O}_{2}\right)=3 \% \\
& \text { Gas sample G2: } \varphi\left(\mathrm{CH}_{4}\right)=70 \%, \varphi\left(\mathrm{CO}_{2}\right)=5 \%, \\
& \varphi\left(\mathrm{C}_{3} \mathrm{H}_{8}\right)=10 \%, \varphi\left(\mathrm{N}_{2}\right)=12 \%, \varphi\left(\mathrm{O}_{2}\right)=3 \% \\
& \text { Gas sample G3: } \varphi\left(\mathrm{CH}_{4}\right)=85 \%, \varphi\left(\mathrm{CO}_{2}\right)=5 \%, \\
& \varphi\left(\mathrm{C}_{3} \mathrm{H}_{8}\right)=5 \%, \varphi\left(\mathrm{N}_{2}\right)=2 \%, \varphi\left(\mathrm{O}_{2}\right)=3 \%
\end{aligned}
$$

The gas samples were produced by Harbin Liming Gas Company; water used in the experiment was the self-made distilled water.

2.3. Procedure. It was shown in Figure 1 that the thermodynamic experiment is similar to the kinetics experiment. However, the main differences were the reactors. The variable 


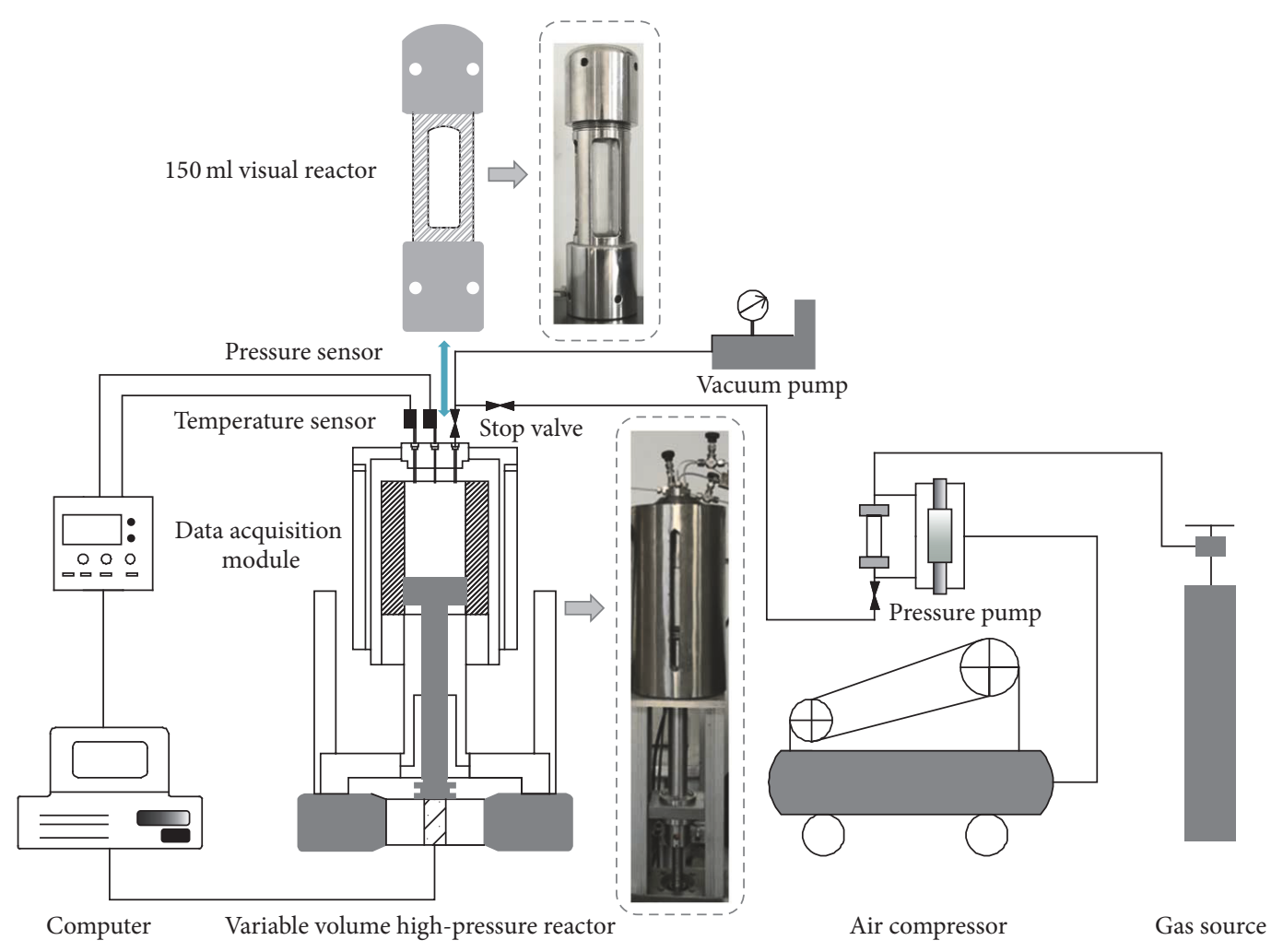

FIgURE 1: The systematic diagram of mine gas hydrate's high-pressure experimental equipment.

volume high-pressure reactor was used in the thermodynamic experiment and the $150 \mathrm{ml}$ visual reactor was used in kinetics experiment.

\subsubsection{Experiment Method and Procedure of Thermodynamics.}

(1) The compound solution was prepared containing $\mathrm{NaCl}$ with the mass fractions of $0 \%, 0.5 \%, 2 \%$, and $3.5 \%$ respectively.

(2) Firstly, debug the data acquisition software to ensure the accuracy of the data collected during the experiment.

(3) Put the prepared solution into the experimental reactor and connect the experimental equipment. Nitrogen was filled into experimental system until the pressure reached $1 \mathrm{MPa}$. Detect the air tightness of system after standing 30 mins and then the experiment system pressure came to $-0.01 \mathrm{MPa}$ using the vacuum pump.

(4) The temperature of thermotank was set up as the initial specified temperature. When the experimental temperature reached the initial temperature; the mix gas was filled into experimental reactor until reaching the initial pressure using pressurization system.

(5) The space of variable volume reactor was narrowed down by industrial computer to make the pressure increase until hydrate formation. Stop compressing the variable volume reactor and when the pressure within stayed constant, enlarge its space to decrease the pressure. The pressure was decreased by $0.2 \mathrm{MPa}$ every 5 hours to make the hydrate decomposition. When the hydrate completely decomposed, the pressure of reactor was increased again and the hydrate formed as well. At the moment, the pressure within was the phase equilibrium pressure under a certain temperature.

(6) According to the above method, three kinds of different gas phase equilibrium temperature and pressure were measured, and the phase equilibrium curves were recorded.

\subsubsection{Experiment Method and Procedure of Kinetics. Quan-} tification of hydrate nucleation process was very difficult. First, hydrate nucleation must be detected. Secondly, in order to obtain the meaningful average value of the nucleation rate, a large number of nuclear tests were needed. Furthermore, the thermodynamic conditions of the experiment must also be controlled.

(1) The compound solution was prepared containing $\mathrm{NaCl}$ with the mass fractions of $0 \%, 0.5 \%, 2 \%$, and $3.5 \%$ respectively, and SDS with the concentration of $0.15,0.30$, 0.45 , and $0.60 \mathrm{~mol} / \mathrm{L}$;

(2)-(4) The procedure was the same as the thermodynamics method.

(5) In the condition of constant temperature, the change of pressure with time was recorded. At the beginning, the pressure decreased constantly due to the dissolution of gas in the liquid phase. When the gas dissolved to become the equilibrium state, the pressure tended to be stable, which was recorded as the starting point of induction time and the ending time was denoted with the formation of hydrate crystal nucleus. 


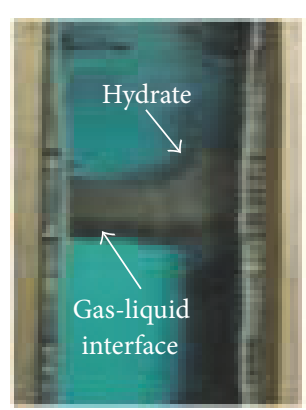

(a)

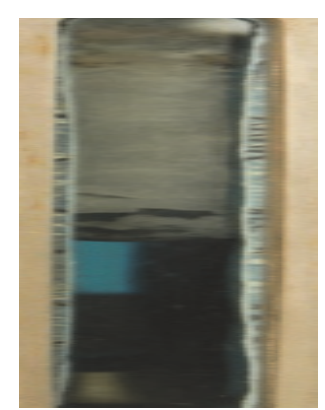

(b)

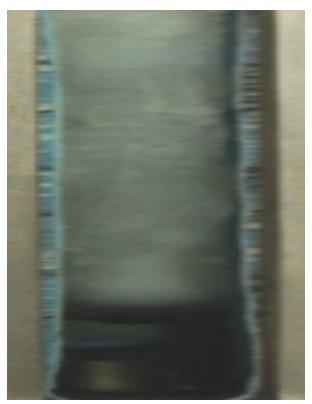

(c)

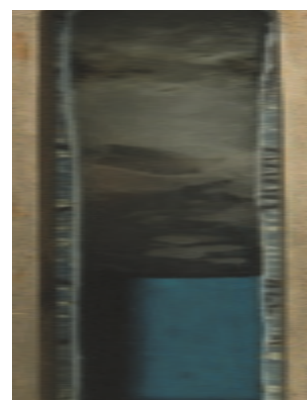

(d)

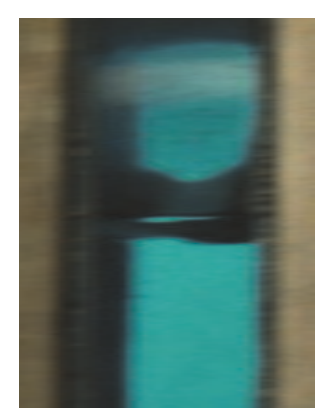

(e)

Figure 2: The formation and dissociation process of hydrate. (a) Initial hydrate formation, (b) hydrate growth rapidly, (c) formation ending stage, (d) hydrate decomposition gradually, and (e) hydrate formation for the second time.

(6) The changes of temperature and pressure of hydrate formation and the growth phenomenon were monitored by the acquisition system and the image recording system.

\section{Equilibrium Conditions of Mine Gas Hydrate Formation in $\mathrm{NaCl}$ System}

At present, the method of determining the phase equilibrium conditions mainly includes direct observation method, temperature search method, quality analysis method, and graphic method [23]. Considering the mine gas is a kind of mixed gas, Tohidi et al. [24] and Schroeter et al. [25] hold that graphic method takes a larger error and pressure search method is not suitable for multisystem and the quality analysis method has a high requirement for the equipment. Therefore, the independent developed reactor for the multicomponent mixed gas hydrate phase equilibrium testing was used to determine the equilibrium parameters incorporating with direct observation method.

Pressure search method is reducing the constant temperature gradually until the hydrate formation, and then heating the same constant temperature by degrees, the hydrate decomposes gradually with the heating process. When the hydrate is completely decomposed, the temperature is reduced by the certain constant temperature and the hydrate forms. At the moment, the temperature and pressure are the phase equilibrium conditions of hydrate. That is to say, the pressure search method is obtaining the pressure conditions of hydrate formation by changing temperature. Nevertheless, the author aimed to get the phase equilibrium pressure under the certain temperature by changing the gas phase volume based on the pressure search method. The hydrate phase equilibrium experiment included 72 groups and the hydrate changing process in each group was similar. As a result, take G1 sample in $\mathrm{NaCl}$ system at the temperature of $278.15 \mathrm{~K}$ as an example to explain the hydrate formation and decomposition process in hydrate phase equilibrium experiment.

The initial pressure and temperature are $1 \mathrm{MPa}$ and $278.15 \mathrm{~K}$. Decreasing the volume of the reactor gradually, the pressure in the reactor was constantly increased. When the pressure was up to $2.1 \mathrm{MPa}$, the hydrate began to generate, as shown in Figure 2(a), and the volume was unchanged. After a certain moment, a large number of hydrates formed, as shown in Figure 2(b). The pressure gradually decreased to $0.8 \mathrm{MPa}$ to reach the equilibrium state, as seen in Figure 2(c). Increase the reactor volume gradually to make sure that the pressure was reduced by $0.1 \mathrm{MPa}$. After every $0.1 \mathrm{MPa}$ reduction, six hours was needed to observe the hydrate. With the pressure decreasing gradually, hydrate decomposed, as shown in Figure 2(d). When the hydrate completely decomposed, the volume was compressed again to ensure the pressure increase by $0.1 \mathrm{MPa}$ and the hydrate formed again, as seen in Figure 2(e). At the moment, the pressure was $1.17 \mathrm{MPa}$. It is shown that the pressure of G1 phase equilibrium under the temperature of $278.15 \mathrm{~K}$ was $1.17 \mathrm{MPa}$. Repeat the above operation and obtain the hydrate phase equilibrium data of different systems and different conditions.

The phase equilibrium results of multicomponent mixed gas hydrate were shown in Figure 3. According to hydrate phase equilibrium curve of three kinds of gas, it was found that the pressure of hydrate formation became higher with the increase of $\mathrm{NaCl}$ concentration under the same temperature, indicating that $\mathrm{NaCl}$ took the inhibitory effect on the formation of gas hydrate. The effect strengthened with the increase of $\mathrm{NaCl}$ concentration. Moreover, in the three kinds of gas in the same $\mathrm{NaCl}$ concentration system, the hydrate phase equilibrium pressure was lower in the gas with higher propane at the same temperature.

\section{Induction Time Distribution of Mine Gas Hydrate Formation in NaCl-SDS System}

4.1. The Mine Gas Hydrate Formation in NaCl-SDS System. $\mathrm{NaCl}$ was reported to change the phase equilibrium conditions of mine gas hydrate formation by many literatures. However, the purpose of this paper was to investigate the effect of propane and SDS- $\mathrm{NaCl}$ compound system on the nucleation kinetics of mine gas hydrate formation. Therefore, to eliminate the influence of $\mathrm{NaCl}$ on the thermodynamic condition of mine gas mixture hydrates formation, the experiment was carried out in the condition of same temperature and the driving force was $1 \mathrm{MPa}$. The phase equilibrium pressure corresponding to the initial temperature has been measured in Figure 2. In this paper, a fully transparent 


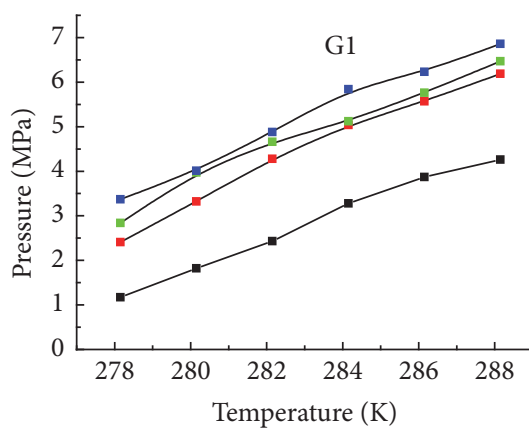

- $\mathrm{NaCl}$ Free $\quad-\quad \mathrm{NaCl}-2 \%$

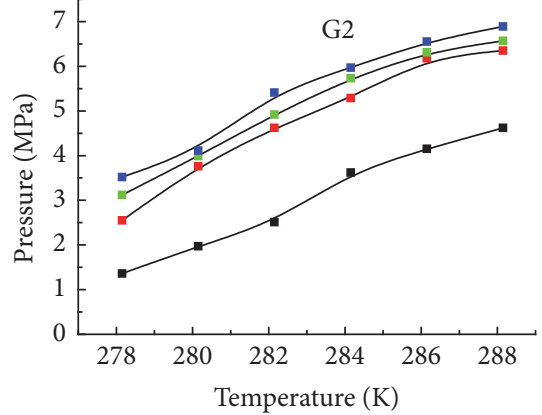

- $\mathrm{NaCl}$ Free $\quad-\square-\mathrm{NaCl}-2 \%$
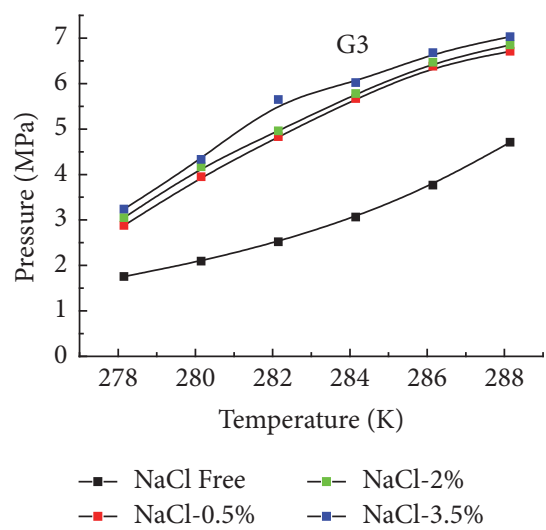

Figure 3: P-T curve of hydration reaction.

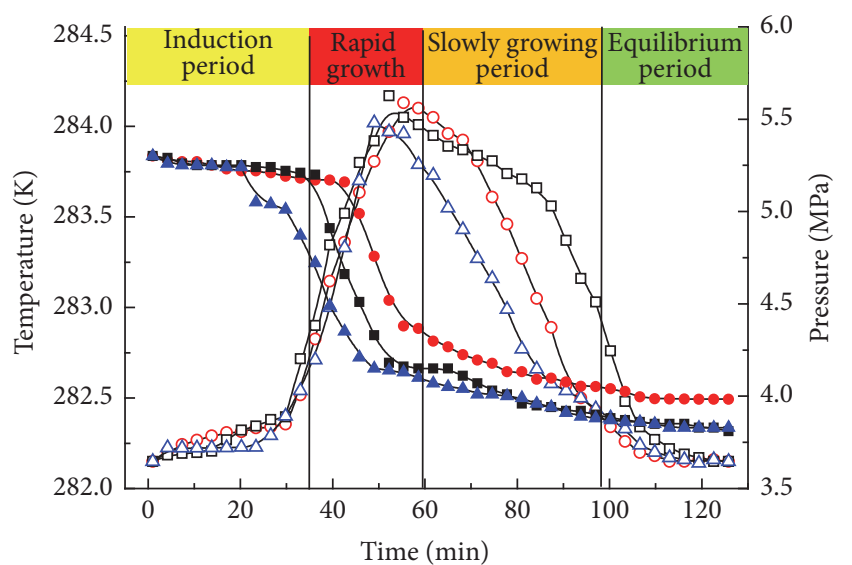

$$
\begin{array}{ll}
\text { Temperature } & \text { Pressure } \\
-\square-\text { First round } & -\bullet-\text { First round } \\
-\square-\text { Second round } & -- \text { - Second round } \\
-\Delta-\text { Third round } & -\Delta-\text { Third round }
\end{array}
$$

FIgURE 4: The curves of mine gas hydrate formation temperature and pressure.

experimental reactor (Figure 1) was used to carry out the hydrate formation kinetic experiment of mine gas mixed gas containing propone and induction time was determined by the direct observation method.

The growth of gas hydrate and the pressure curve in each experiment system was similar, taking the experimental system I-1 (the first); for example, the compound solution with the mass fraction $0.5 \%$ of $\mathrm{NaCl}$ and the concentration $0.15 \mathrm{~mol} / \mathrm{L}$ of SDS was poured into the full transparent and high-pressure reactor, and G1 was inflated until the pressure reached $5.3 \mathrm{MPa}$ when the temperature was $282.15 \mathrm{~K}$, monitoring the process of mine gas hydrate formation and controlling the temperature constant. The flocculation appeared in the reactor when the temperature was up to $282.15 \mathrm{~K}$ as shown in Figure 4. For the reason of the appearance of NaCl-SDS white solid precipitation, the exact growth point could not be determined when the amount of mine gas hydrate formation was small (Figure 5(a)). Up to $54 \mathrm{~min}$ of the experiment, on the top of reactor central, a small amount of white iceshaped hydrate crystal appeared with the pressure $4.45 \mathrm{MPa}$ (Figure 5(b)). With the experiment proceeding to $82 \mathrm{~min}$, the white hydrate crystal grew rapidly in the reactor and a large amount of ice-shaped hydrate mixed with $\mathrm{NaCl}$ SDS flocculation solid and mine gas hydrate emerged under the gas-liquid interface, and, contrastively, on the top of that, the hydrate continued to grow along the inner wall of reactor (Figure 5(c)). When the experiment reached $97 \mathrm{~min}$, the white mine gas hydrate crystal presented block shape and continued to grow, and the pressure was $3.98 \mathrm{MPa}$ and no longer decreased at $116 \mathrm{~min}$, and the hydrate formation finished (Figure 5(d)). To reduce the induction time, random, different kinetic experiments were carried out in 3 rounds and the experimental results were of average value. The kinetics experimental system and the results were summarized in Tables 1, 2, and 3 .

\subsection{The Analysis and Discussion of the Nucleation \\ Kinetics Experimental Results of Mine Gas Hydrate in $\mathrm{NaCl}$-SDS System}

4.2.1. Analysis and Discussion on the Effect of NaCl-SDS Compound Solution. The experimental results indicated that the induction time of mine gas hydrate formation in $\mathrm{NaCl}-\mathrm{SDS}$ system was obviously shorter than that in SDS system, as seen in Figure 6, which showed that the addition of $\mathrm{NaCl}$ reduced the induction time of hydrate formation which attributed that $\mathrm{NaCl}$ could help to promote the nucleation of hydrate. From Figure 6, it was concluded that the induction time constantly decreased with an increase in SDS concentration on the condition of the same $\mathrm{NaCl}$ concentration. However, Figure 6 expressed that the induction time increased with increasing concentration of $\mathrm{NaCl}$ on the condition of the same SDS concentration. As a result, it was found that the induction time of mine gas hydrate formation was shorter with the increase of the SDS concentration and the reduction of the $\mathrm{NaCl}$ concentration within the experimental range.

It was analyzed that the ionic surfactant (SDS) could have the electrostatic interaction between the ions by the influence of $\mathrm{NaCl}$ solution, which reduced the repulsion of the electric 


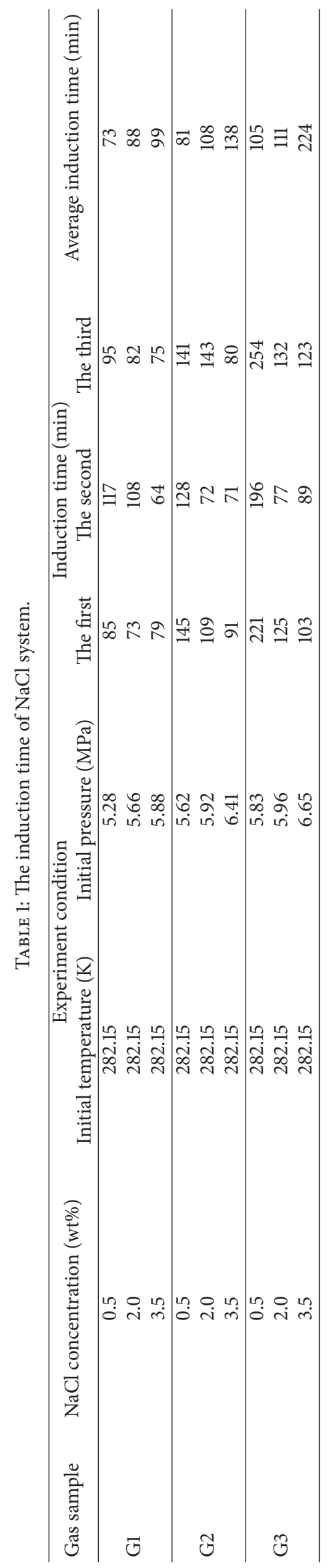




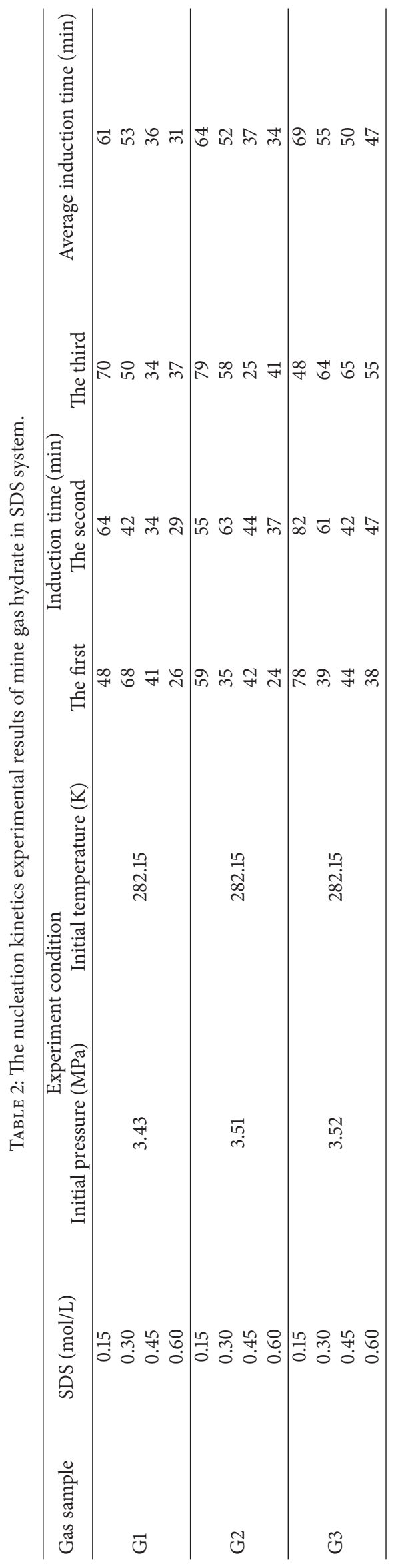




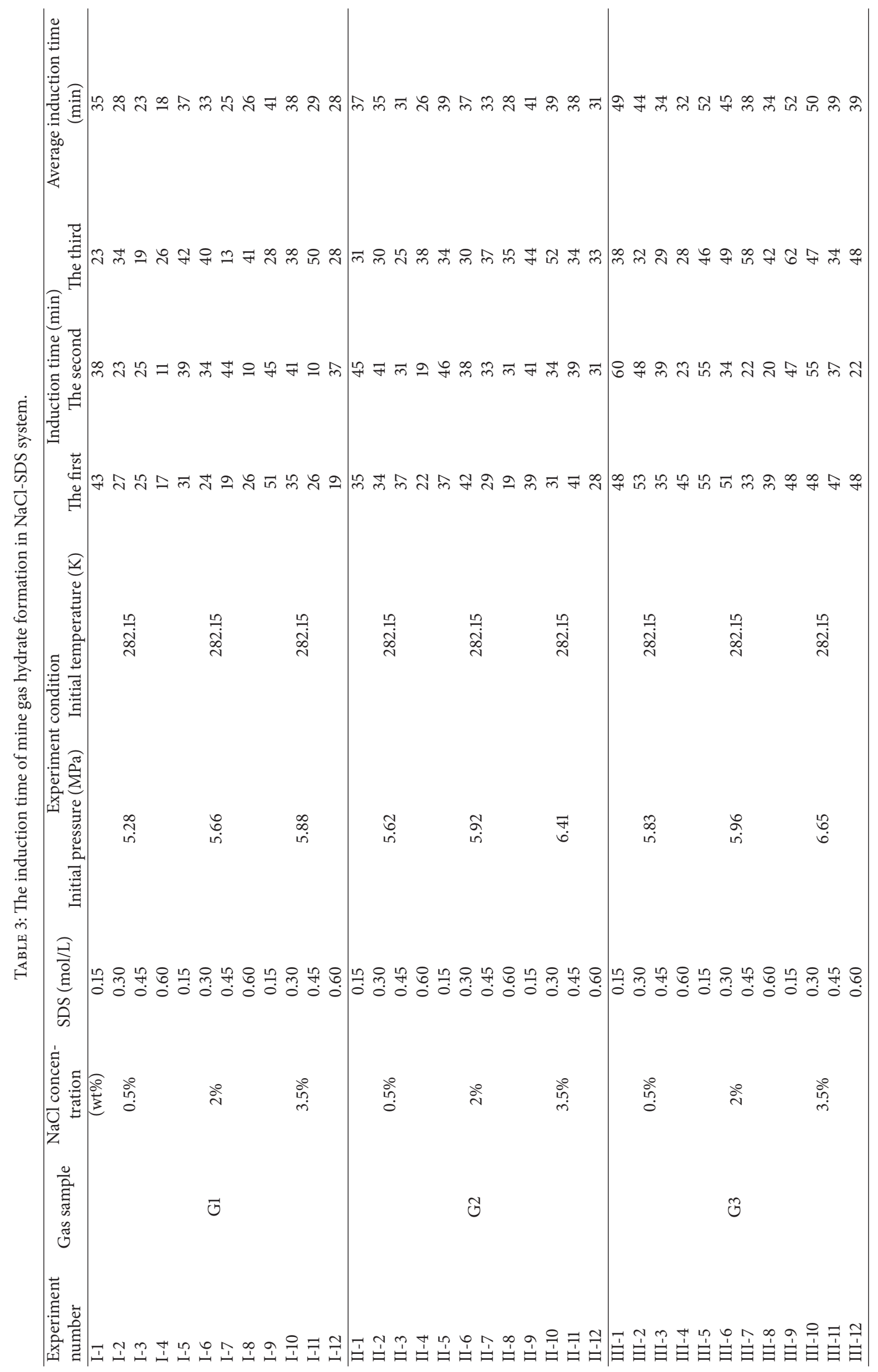




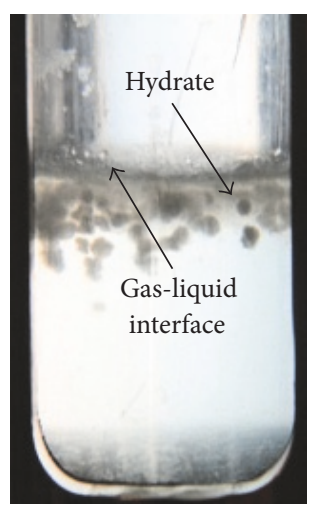

(a) $10 \mathrm{~min}$

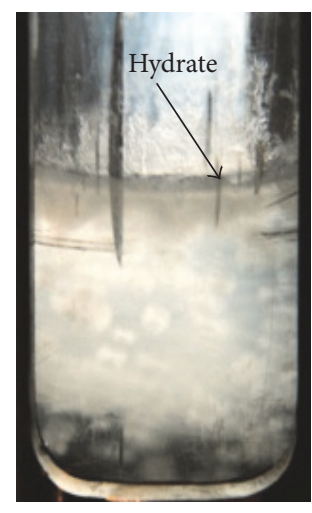

(b) $54 \mathrm{~min}$

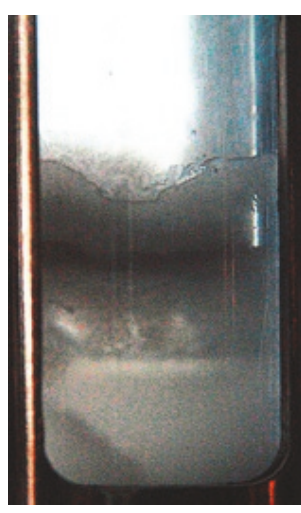

(c) $82 \mathrm{~min}$

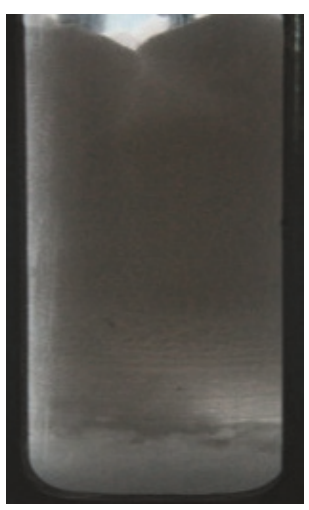

(d) $116 \mathrm{~min}$

FIgURE 5: The process of mine gas hydrate formation in NaCl-SDS system.

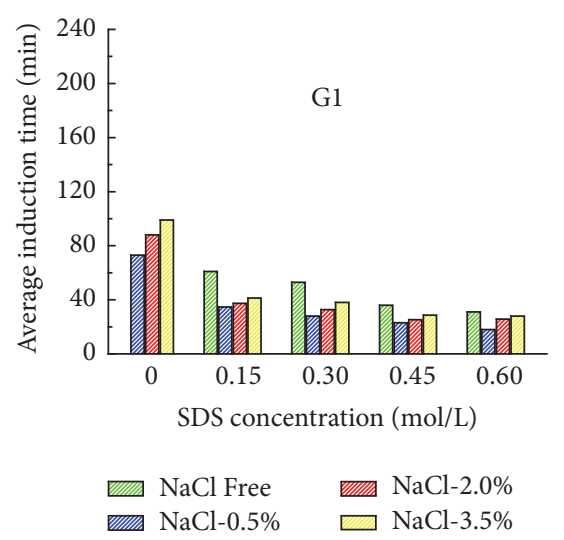

(a)
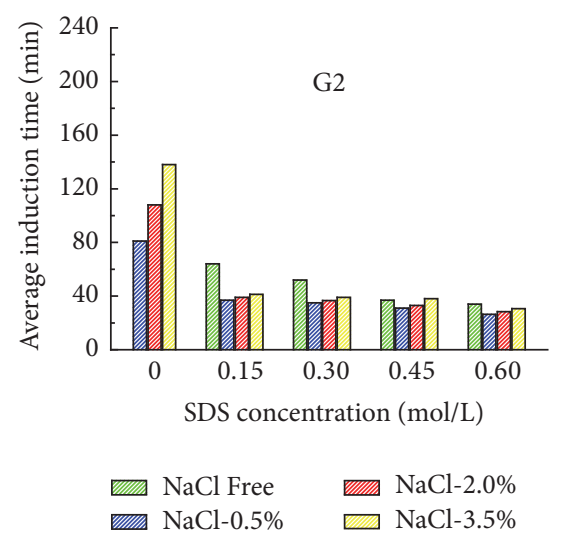

(b)

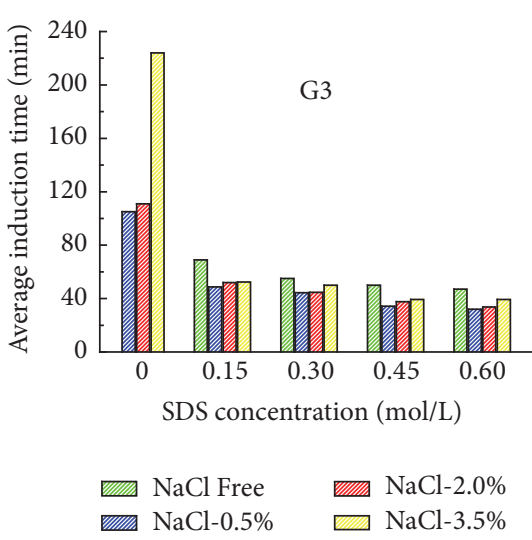

(c)

FIGURE 6: The induction time distribution of gas hydrate formation in different gas groups with the changing of SDS concentration.

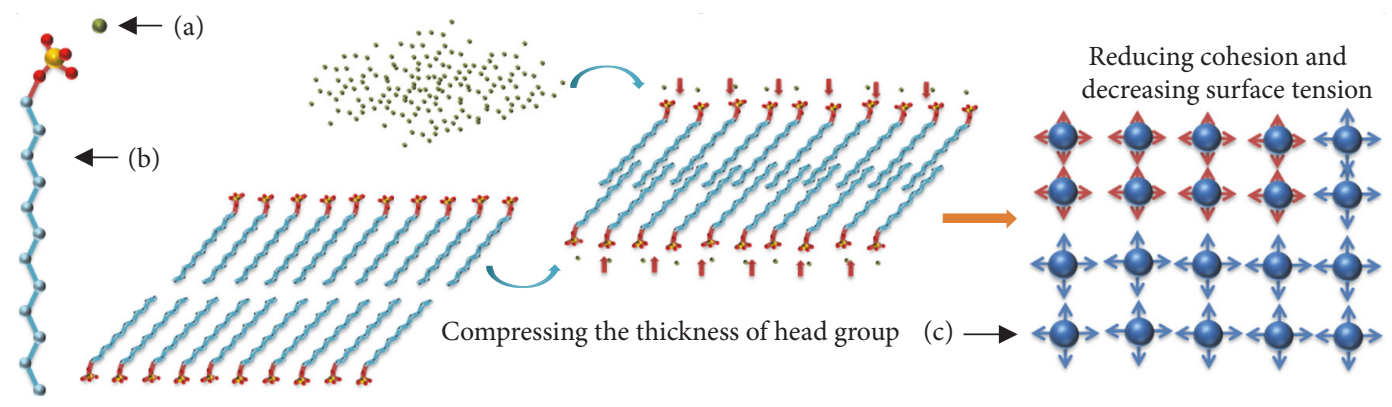

FIgURE 7: The effect of $\mathrm{NaCl}$ on SDS. (a) The sodium counterion, (b) SDS molecule, and (c) water molecule.

double layers of head group, so that the thickness of that was compressed [26], and the difficulty of SDS surface adsorption was reduced (as shown in Figure 7). Simultaneously, part of the hydrophilic based charge of SDS was neutralized by the counterion of $\mathrm{NaCl}$ solution and the phase potential was reduced and the cohesion of water molecules within the gas-liquid interface was decreased, which resulted in a decrease of the surface tension [27]. The neutralization ability of $\mathrm{NaCl}$ solution was stronger when the $\mathrm{NaCl}$ mass fraction was higher and the number of the counterions was larger.
The essential role of SDS in the hydration process was to decrease the surface tension and increase the gas solubility; however, SDS presented as the micelles by the influence of $\mathrm{NaCl}$ solution which could enhance the reducing effect of SDS on the surface tension and increase the solubility of the mine gas in solution and promote the crystallization rate, so that the induction time of mine gas hydrate was shortened. The author believed that $\mathrm{NaCl}$ solution made the function of enhancing the reduction effect of SDS on the surface tension of liquid phase and it could make low concentration of SDS 


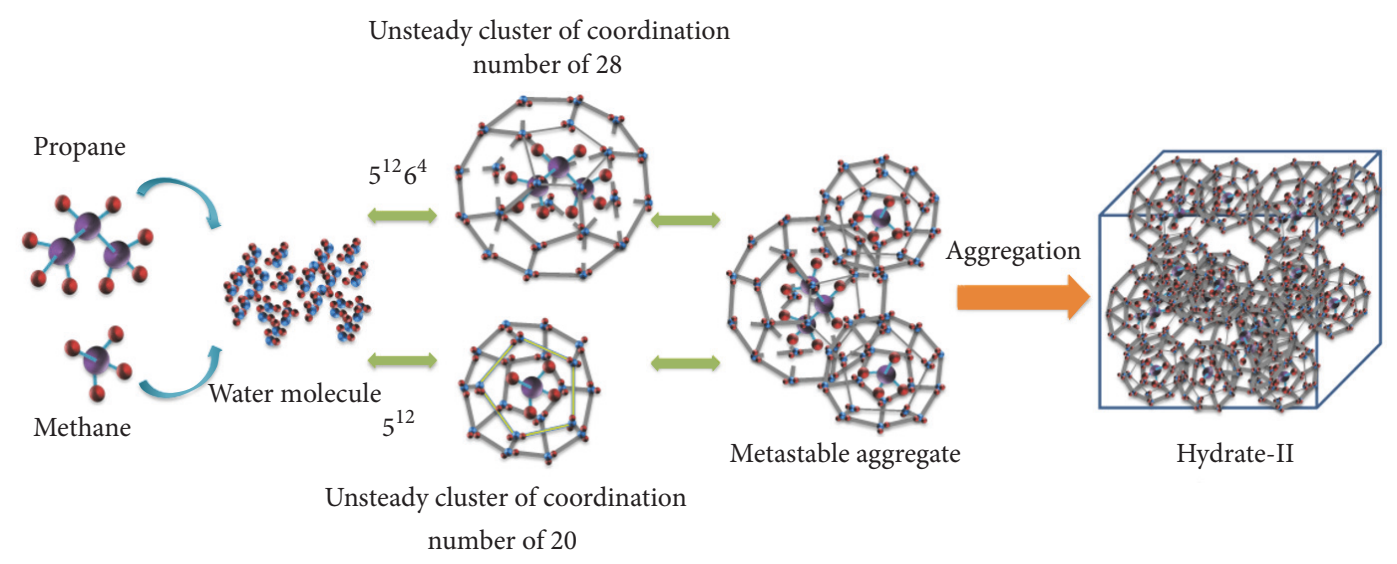

FIGURE 8: The synergistic nucleation process of methane and propane.

have the equal effect with that of high concentration. Sun et al. [28] held the opinion that when SDS concentration was up to the critical micelle concentration, the effect of SDS on reducing surface tension reached the largest point.

$\mathrm{NaCl}$ can strengthen the effect of SDS on reducing the surface tension and promote the SDS utility. However, in $\mathrm{NaCl}$ solution, the gas molecules first dissolved in liquid phase in the form of molecular diffusion and were surrounded by water clusters loosely and formed a kind of cage structure which was extremely unstable and continuously collided with the surrounding cluster until the formation of the relatively stable cage structure. Ion charge field changed the ionization equilibrium of the original system [29], reduced the contact of gas molecules and water molecules, and reduced the collision of water clusters, thereby affecting the formation of water molecules clusters around gas molecule stably. To offset the resistance of $\mathrm{Na}^{+}$and $\mathrm{Cl}^{-}$and build the basic environment for gas hydrate formation, a certain "driving force" was provided to balance the above force, which resulted in slowing the nucleation rate of gas hydrate and prolonging the induction time. Simultaneously, with the increase of $\mathrm{NaCl}$ concentration, the time was longer. Therefore, the role of $\mathrm{NaCl}$ in SDS system took two aspects and, in this paper, the induction time of mine gas hydrate formation was shortened with the increase of $\mathrm{NaCl}$ mass fraction, which indicated that adding a small amount of $\mathrm{NaCl}$ can shorten the induction time of gas hydrate formation in the presence of SDS. However, the optimal concentration of $\mathrm{NaCl}$ and SDS still needed further study.

4.2.2. Analysis of the Influence of Mine Gas Composition on the Induction Time. According to Figure 6, it is shown that the induction time of three kinds of mine gas ranged in an ascending order for G1, G2, and G3 under the condition of the same $\mathrm{NaCl}-\mathrm{SDS}$ concentration, with the gas component ratio of G1 (methane $=55 \%$; propane $=15 \%)$, G2 (methane $=70 \%$; propane $=10 \%)$, and G3 (methane $=85 \%$; propane $=5 \%$ ), which indicated that the effects of methane concentration and propane concentration on the nucleation process of mine gas hydrate were the main factors. As the induction time distribution is described, the induction time of mine gas hydrate formation was shortened with the reduction in methane concentration and increase in propane concentration. In this paper, in G1 with the highest propane concentration and different mass fraction of $\mathrm{NaCl}$, the average induction time of the hydrate formation was $4.5 \mathrm{~min}$ and $12.25 \mathrm{~min}$, which was shorter than G2 and G3 within the same mass fraction of $\mathrm{NaCl}$. Sloan and Fleyfel [30] and Christiansen and Sloan [31] found that the formation of crystal nucleus in the critical size needed to experience several periods, which were gas molecule dissolution, unstable clusters formation, metastable aggregates formation, and stable crystal nucleus. The coordination number of water molecules in the unstable clusters was somewhat different due to the size differences of gas molecules (coordination number of methane, 20; coordination number of propane, 28) [32]. The hydrate-I was constituted by pores $5^{12}$ and $5^{12} 6^{2}$ (with pore ratio $1: 3$ ) and hydrate-II included pores $5^{12}$ and $5^{12} 6^{4}$ (with pore ratio $2: 1$ ) [33-35], in which the numbers of water molecules of $5^{12}$, $5^{12} 6^{2}$, and $5^{12} 6^{4}$ were 20,24 , and 28 , respectively. Based on the analysis above, it was concluded that the mine gas sample in the experiment contained methane and propane and formed the unstable cluster with the coordination number of 20 and 28 after dissolving in water. And then the two kinds of unstable clusters aggregated into the metastable aggregates directly through sharing a common surface, not experiencing the transferred process from the unstable cluster with the coordination number of 20 to that of 24 , and the transferred process from 28 to 20 and finally gathered to form hydrate-II crystal nucleus (show in Figure 8).

Due to reversible conversion between the unstable clusters and the metastable aggregates, only a portion of the metastable aggregates could aggregate together to form the stable crystal nucleus. However, the concentration ratios of methane and propane were $11: 3,21: 3$, and $51: 3$ in G1, G2, and G3, indicating that the unstable cluster with coordination number of 20 was sufficient in the process of three kinds of mine gas hydrate nucleation. The number of unstable clusters with the coordination number of 28 determined the induction time. When the unstable clusters of methane were enough, the number of unstable clusters with the coordination number of 28 increased with an increase of 
propane concentration in different gas sample systems and the probability of aggregation to form the stable crystal nucleus was higher as well. Therefore, the induction of hydrate formation reduced with the decrease in methane concentration and increase in propane concentration within the experimental range.

\section{Conclusions}

The induction time of mine gas hydrate formation in $\mathrm{NaCl}$ SDS system was significantly shorter than that of SDS system. It was analyzed that $\mathrm{NaCl}$ took as two influencing aspects: (1) $\mathrm{NaCl}$ could enhance the reducing effect of SDS on the gasliquid surface tension, increase the solubility of the mine gas due to the presence of SDS micelles, promote the nucleation process of mine gas hydrate, and reduce the induction time. (2) $\mathrm{NaCl}$ can destroy the water cluster structure and inhibit the hydrate formation. According to the experimental results, it was found that, by adding a small amount of $\mathrm{NaCl}$ to SDS solution, the induction time of hydrate was shortened. In this experiment, the mine gas hydrate was II, not experiencing the transformation of different coordination number of singe component gas in the nucleation process. The metastable aggregates and hydrate lattice were formed by methane and propane through sharing a common surface. In this experiment, the induction time of gas hydrate formation was reduced with the decrease of methane concentration and increase of propane concentration. It is necessary and significant that the effect of propane and NaCl-SDS compound solution on mine gas hydrate separation rate and methane recovery rate will be studied in the following experiment.

\section{Conflicts of Interest}

The authors declare that they have no conflicts of interest.

\section{Acknowledgments}

This work was supported by National Natural Science Foundation of China (nos. 51404102, 51334005, and 51274267).

\section{References}

[1] A. I. Reshetnikov, N. N. Paramonova, and A. A. Shashkov, "An evaluation of historical methane emissions from the Soviet gas industry," Journal of Geophysical Research Atmospheres, vol. 105, no. 3, Article ID 1999JD900761, pp. 3517-3529, 2000.

[2] H. N. Chen, W. D. Zhang, and L. Y. Xie, "Reserves and development status of global unconventional gas," Fault-Block Oil and Gas Field, vol. 17, pp. 439-442, 2010.

[3] I. J. Lakatos and J. Lakatos-Szabo, "Role of conventional and unconventional hydrocarbons in the 21st century: comparison of resources, reserves, recovery factors and technologies," in Proceedings of the EUROPEC/EAGE Conference and Exhibition, Amsterdam, The Netherlands, June 2009.

[4] J. Liu, "Status quo and countermeasure analysis of CBM/CMM recovery and utilization in China," China Coalbed Methane, vol. 12, pp. 44-47, 2015.
[5] T. Utaki, "Development of coal mine methane concentration technology for reduction of greenhouse gas emissions," Science China Technological Sciences, vol. 53, no. 1, pp. 28-32, 2010.

[6] Q. Wu, Experimental Study on the Hydration Mechanism of the Mine Gas, Department of Safety Engineering, China University of Mining \& Technology, 2005.

[7] Q. Wu, Q. Zhang, and B. Zhang, "Influence of super-absorbent polymer on the growth rate of gas hydrate," Safety Science, vol. 50, no. 4, pp. 865-868, 2012.

[8] S. A. Shepeleva and V. V. Dyrdin, "Gas emission under coal and gas outbursts," Journal of Mining Science, vol. 47, no. 5, pp. 660663,2011

[9] U. Karaaslan and P. Mahmut, "Effect of surfactants on hydrate formation rate," Annals of the New York Academy of Sciences, vol. 912, no. 1, pp. 735-743, 2000.

[10] Y. Zhong and R. E. Rogers, "Surfactant effects on gas hydrate formation," Chemical Engineering Science, vol. 55, no. 19, pp. $4175-4187,2000$

[11] A. Mohammadi, M. Manteghian, A. Haghtalab, A. H. Mohammadi, and M. Rahmati-Abkenar, "Kinetic study of carbon dioxide hydrate formation in presence of silver nanoparticles and SDS," Chemical Engineering Journal, vol. 237, pp. 387-395, 2014.

[12] D. D. Link, E. P. Ladner, H. A. Elsen, and C. E. Taylor, "Formation and dissociation studies for optimizing the uptake of methane by methane hydrates," Fluid Phase Equilibria, vol. 211, no. 1, pp. 1-10, 2003.

[13] Q. Zhang, Q. Wu, B. Zhang, X. Gao, and C. Liu, "Effect of drywater on methane separation from mine gas via the hydrate formation," Journal of China University of Mining and Technology, vol. 45, no. 5, pp. 907-914, 2016.

[14] Q. Wu, Y. M. Zhu, and B. Y. Zhang, "Effects of sodium dodecyl sulfate and kaolin on low-concentration mine gas hydration separation," Journal of the Chemical Industry and Engineering Society of China, vol. 60, no. 5, pp. 1193-1198, 2009.

[15] B. Y. Zhang, Q. Zhang, Q. Wu, C. L. Liu, and Y. P. Cheng, "Effect of super-absorbent polymer on hydration separation rate of mine gas," Journal of China University of Mining Technology, vol. 42, pp. 382-387, 2013.

[16] M. E. Wise, K. J. Baustian, T. Koop, M. A. Freedman, E. J. Jensen, and M. A. Tolbert, "Depositional ice nucleation onto crystalline hydrated $\mathrm{NaCl}$ particles: a new mechanism for ice formation in the troposphere," Atmospheric Chemistry and Physics, vol. 12, no. 2, pp. 1121-1134, 2012.

[17] M. Yang, Y. Song, Y. Liu, Y. Chen, and Q. Li, "Influence of pore size, salinity and gas composition upon the hydrate formation conditions," Chinese Journal of Chemical Engineering, vol. 18, no. 2, pp. 292-296, 2010.

[18] A. H. Mohammadi and D. Richon, "Methane hydrate phase equilibrium in the presence of salt $\left(\mathrm{NaCl}, \mathrm{KCl}\right.$, or $\left.\mathrm{CaCl}_{2}\right)+$ ethylene glycol or salt $\left(\mathrm{NaCl}, \mathrm{KCl}\right.$, or $\left.\mathrm{CaCl}_{2}\right)+$ methanol aqueous solution: Experimental determination of dissociation condition," Journal of Chemical Thermodynamics, vol. 41, no. 12, pp. 1374-1377, 2009.

[19] S. L. Wang, H. J. Yu, and Q. S. Shi, "Effect of compound additives on natural gas hydrate formation in different systems," Natural Gas Chemical Industry, vol. 60, pp. 1193-1198, 2009.

[20] Z. T. Ward, M. L. Johns, E. F. May, C. A. Koh, and Z. M. Aman, "Crystal growth phenomena of $\mathrm{CH}_{4}+\mathrm{C}_{3} \mathrm{H}_{8}+\mathrm{CO}_{2}$ ternary gas hydrate systems," Journal of Natural Gas Science and Engineering, vol. 35, pp. 1426-1434, 2016. 
[21] L.-T. Chen, C.-Y. Sun, G.-J. Chen, and Y.-Q. Nie, “Thermodynamics model of predicting gas hydrate in porous media based on reaction-adsorption two-step formation mechanism," Industrial and Engineering Chemistry Research, vol. 49, no. 8, pp. 3936-3943, 2010.

[22] M. R. Prado, Y. Cazares, and K. C. Janda, "Toward the efficient production of methane/propane double hydrate," Industrial and Engineering Chemistry Research, vol. 48, no. 11, pp. 5160-5164, 2009.

[23] X. Li, H. Wu, Z. Feng, L. Tang, and S. Fan, "Prediction of equilibrium hydrate formation conditions for gas mixtures using the statistical associating fluid theory equation of state," Acta Chimica Sinica, vol. 65, pp. 59-66, 2007.

[24] B. Tohidi, A. Danesh, A. C. Todd, R. W. Burgass, and K. K. ØStergaard, "Equilibrium data and thermodynamic modelling of cyclopentane and neopentane hydrates," Fluid Phase Equilibria, vol. 138, no. 1-2, pp. 241-250, 1997.

[25] J. P. Schroeter, R. Kobayashi, and M. A. Hildebrand, "Hydrate decomposition conditions in the system hydrogen sulfidemethane-propane," Industrial \& Engineering Chemistry Fundamentals, vol. 22, no. 4, pp. 361-364, 1983.

[26] R. A. Böckmann, A. Hac, T. Heimburg, and H. Grubmüller, "Effect of sodium chloride on a lipid bilayer," Biophysical Journal, vol. 85, no. 3, pp. 1647-1655, 2003.

[27] J. George and L. Sreejith, "Effect of added brine on polymersurfactant interaction," Journal of Applied Pharmaceutical Science, vol. 1, no. 5, pp. 182-187, 2011.

[28] C.-Y. Sun, G.-J. Chen, C.-F. Ma, Q. Huang, H. Luo, and Q.-P. Li, "The growth kinetics of hydrate film on the surface of gas bubble suspended in water or aqueous surfactant solution," Journal of Crystal Growth, vol. 306, no. 2, pp. 491-499, 2007.

[29] S. Sun, C. Liu, Y. Ye, and Q. Jiang, "Dissociation conditions and influencing factors of methane hydrate in chloride salt solution under high pressure," Acta Physico-Chimica Sinica, vol. 27, pp. 2773-2778, 2011.

[30] E. D. Sloan and F. Fleyfel, "A molecular mechanism for gas hydrate nucleation from ice," AIChE Journal, vol. 37, no. 9, pp. 1281-1292, 1991.

[31] R. L. Christiansen and E. D. Sloan, "Mechanisms and Kinetics of Hydrate Formation," Annals of the New York Academy of Sciences, vol. 715, no. 1, pp. 283-305, 1994.

[32] E. D. Sloan, Clathrate Hydrate of Natural Gases, Taylor \& Francis Group LLC, New York, NY, USA, 2008.

[33] B. Tohidi, A. Danesh, A. C. Todd, and R. W. Burgass, "Hydratefree zone for synthetic and real reservoir fluids in the presence of saline water," Chemical Engineering Science, vol. 52, no. 19, pp. 3257-3263, 1997.

[34] F. E. Anderson and J. M. Prausnitz, "Inhibition of gas hydrates by methanol," AIChE Journal, vol. 32, no. 8, pp. 1321-1333, 1986.

[35] J. Munck, S. Skjold-Jørgensen, and P. Rasmussen, "Computations of the formation of gas hydrates," Chemical Engineering Science, vol. 43, no. 10, pp. 2661-2672, 1988. 

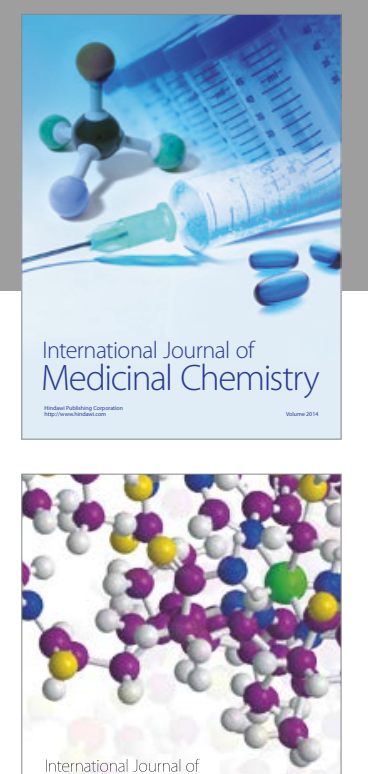

Carbohydrate Chemistry

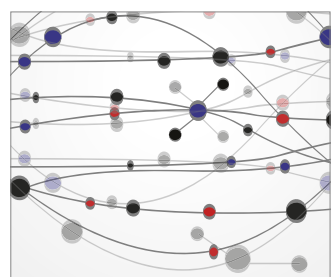

The Scientific World Journal
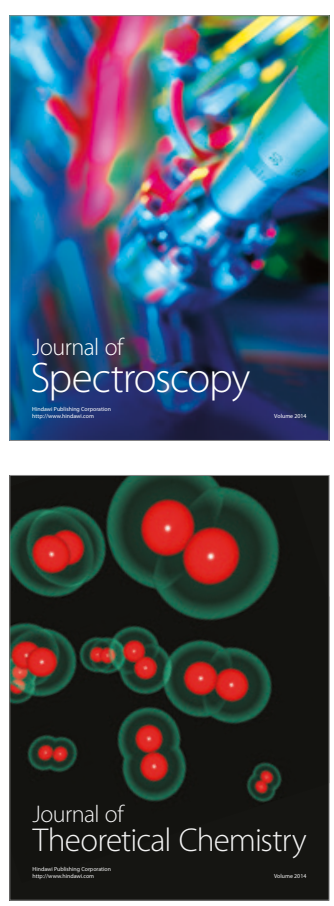
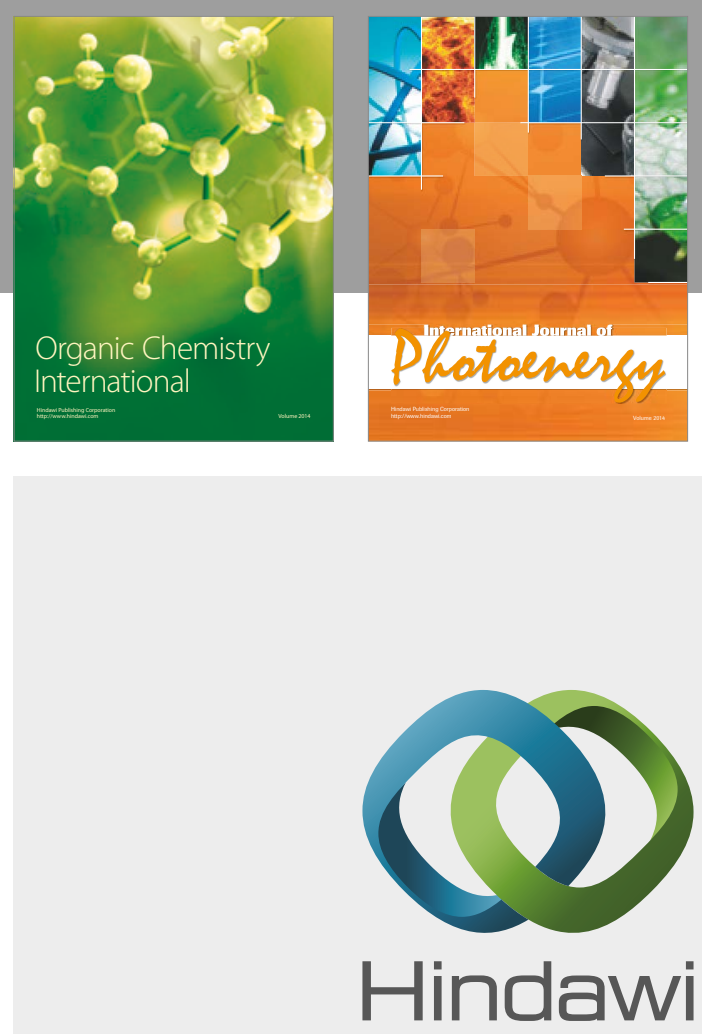

Submit your manuscripts at

https://www.hindawi.com

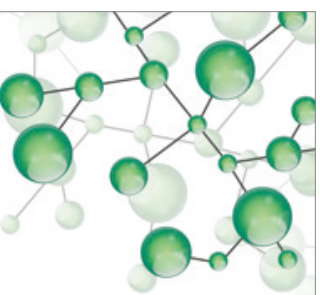

International Journal of

Inorganic Chemistry

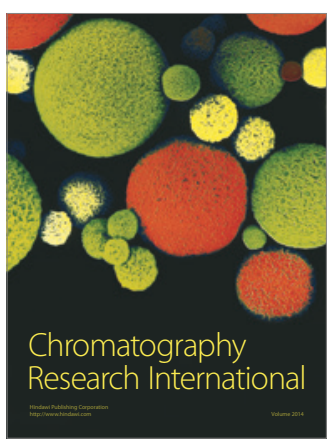

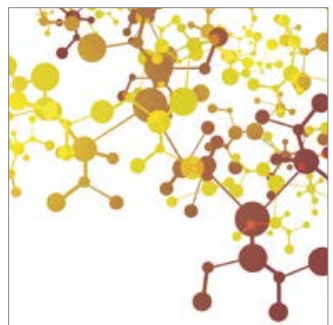

Applied Chemistry
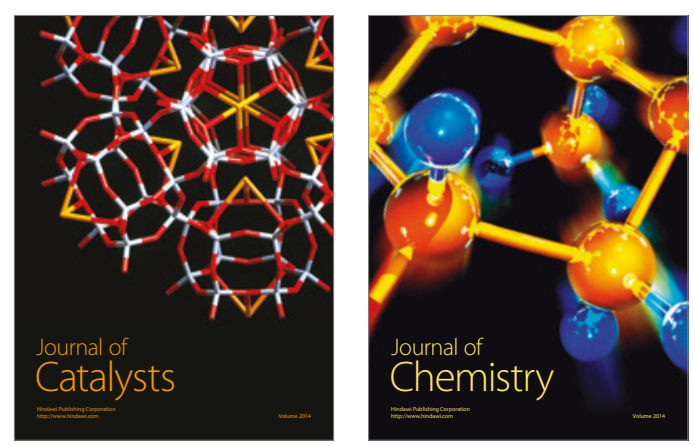
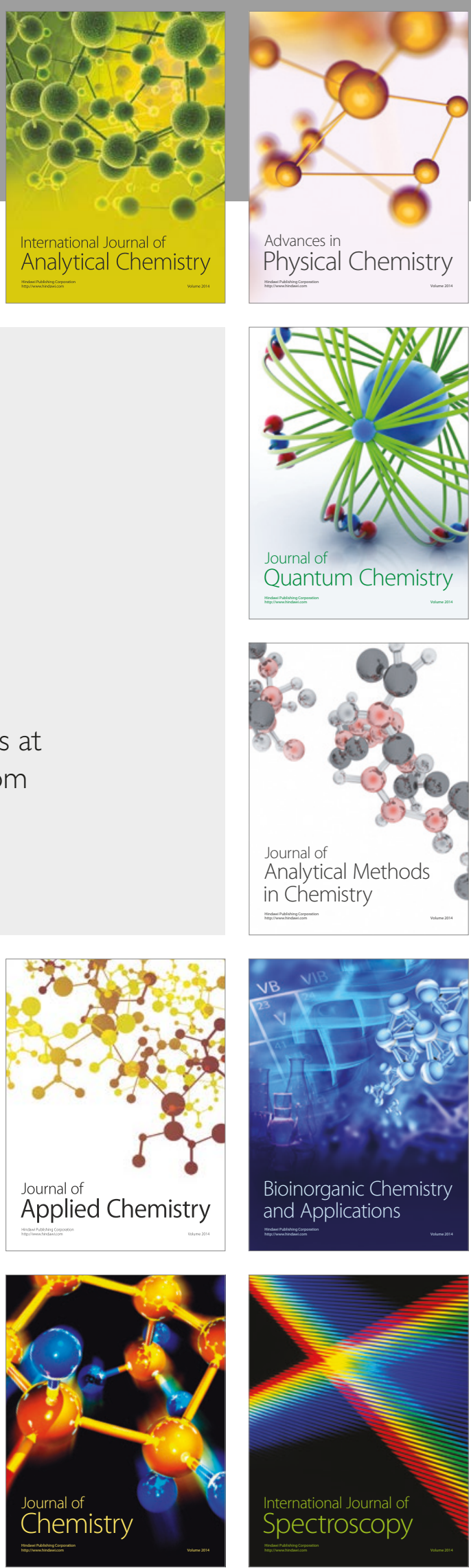